\title{
Molecular insights into the benefits of nicotine on memory and cognition (Review)
}

\author{
AHMAD ALHOWAIL \\ Department of Pharmacology and Toxicology, College of Pharmacy, \\ Qassim University, Buraydah 52571, Qassim, Kingdom of Saudi Arabia
}

Received July 15, 2020; Accepted October 13, 2020

DOI: $10.3892 / \mathrm{mmr} .2021 .12037$

\begin{abstract}
The health risks of nicotine are well known, but there is some evidence of its beneficial effects on cognitive function. The present review focused on the reported benefits of nicotine in the brain and summarizes the associated underlying mechanisms. Nicotine administration can improve cognitive impairment in Alzheimer's disease (AD), and dyskinesia and memory impairment in Parkinson's disease (PD). In terms of its mechanism of action, nicotine slows the progression of $\mathrm{PD}$ by inhibiting Sirtuin 6, a stress-responsive protein deacetylase, thereby decreasing neuronal apoptosis and improving neuronal survival. In AD, nicotine improves cognitive impairment by enhancing protein kinase $\mathrm{B}$ (also referred to as Akt) activity and stimulating phosphoinositide 3-kinase/Akt signaling, which regulates learning and memory processes. Nicotine may also activate thyroid receptor signaling pathways to improve memory impairment caused by hypothyroidism. In healthy individuals, nicotine improves memory impairment caused by sleep deprivation by enhancing the phosphorylation of calmodulin-dependent protein kinase II, an essential regulator of cell proliferation and synaptic plasticity. Furthermore, nicotine may improve memory function through its effect on chromatin modification via the inhibition of histone deacetylases, which causes transcriptional changes in memory-related genes. Finally, nicotine administration has been demonstrated to rescue long-term potentiation in individuals with sleep deprivation, AD, chronic stress and hypothyroidism, primarily by desensitizing $\alpha_{7}$ nicotinic acetylcholine receptors. To conclude, nicotine has several cognitive benefits in healthy individuals, as well as in those with cognitive dysfunction associated with various diseases. However, further research
\end{abstract}

Correspondence to: Dr Ahmad Alhowail, Department of Pharmacology and Toxicology, College of Pharmacy, Qassim University, 4711 King Abdulaziz Road, Buraydah 52571, Qassim, Kingdom of Saudi Arabia

E-mail: aalhowail@qu.edu.sa

Key words: nicotine, memory impairment, protein kinases, histone deacetylases, hypothyroidism is required to shed light on the effect of acute and chronic nicotine treatment on memory function.

\section{Contents}

1. Introduction

2. Benefits of nicotine in Alzheimer's disease (AD)

3. Benefits of nicotine in Parkinson's disease (PD)

4. Benefits of nicotine on memory processes in patients with thyroid disease

5. Effects of nicotine on cognitive function in healthy individuals

6. Nicotine-induced chromatin modifications may improve memory and learning

7. Electrophysiological effects of nicotine: Strengthening synapses

8. Conclusions

\section{Introduction}

Nicotine, or 3-(1-Methylpyrrolidin-2-yl) pyridine, is an alkaloid that is found in the tobacco plant $(1,2)$. Nicotine use can lead to a number of health complications, including heart and lung diseases, and increases the risk of cancer occurrence (3) and the susceptibility to several infectious diseases, including tuberculosis, pneumonia and sexually transmitted diseases such as chlamydia (4). However, increasing evidence suggests that nicotine also has beneficial health effects, particularly in terms cognitive function.

Nicotine acts as an agonist of nicotinic cholinergic receptors (nAChRs), which are found in both the central nervous system (CNS) and the peripheral nervous system $(2,5,6)$. Each nAChR comprises five $\alpha$ or $\beta$ subunits (7). There are nine potential $\alpha$ subunits and three $\beta$ subunits, and different $\mathrm{nAChR}$ receptor subtypes possess varying compositions of these subunits $(8,9)$. The most abundant receptor subtypes present in the human brain are $\alpha_{4} \beta_{2}, \alpha_{3} \beta_{4}$ (heterogenic) and $\alpha_{7}$ (homomeric) (10). The $\alpha_{3} \beta_{4} \mathrm{nAChR}$ is known to mediate the cardiovascular effects of nicotine (11), while the homomeric $\alpha_{7} \mathrm{nAChR}$ is speculated to be involved in synaptic transmission, as well as in learning and sensory gating $(12,13)$. Stimulation of $\mathrm{nAChRs}$ in the CNS by 
nicotine or acetylcholine regulates the release of a variety of neurotransmitters, such as dopamine, glutamate, serotonin, norepinephrine and $\gamma$-aminobutyric acid $(14,15)$. Therefore, alterations in the expression or function of $\mathrm{nAChRs}$, as a result of a disease, may alter the release of other neurotransmitters and, thus, affect brain function.

It is commonly known that long-term exposure to nicotine causes nAChR desensitization (16), leading to memory impairment in otherwise healthy individuals (17). Such nicotine-induced cognitive dysfunction is associated with several mechanisms, including activation of the phosphodiesterase-5 (PDE-5) signaling pathway and inhibition of estrogen biosynthesis $(18,19)$. In particular, nicotine stimulates the expression of PDE-5 $(19,20)$, which plays a role in cleaving cyclic guanosine monophosphate and cyclic adenosine monophosphate that activate downstream signaling pathways contributing to memory impairment (21-23). Nicotine also blocks estrogen synthase (aromatase) in the brain, which is important for estrogen biosynthesis $(18,24)$. Estrogen activates estrogen receptors in the brain, which function as transcriptional factors and enhance the expression of several neurotransmitters (including glutamate, acetylcholine, serotonin and noradrenaline), and thus stimulate the neuronal circuits required for memory encoding (25). Therefore, alterations in estrogen biosynthesis due to nicotine $(20,26)$, as well as the nicotine-induced elevation of PDE-5 levels, can lead to cognitive impairment in healthy individuals.

In contrast to these detrimental effects of nicotine on cognitive function, some studies report that nicotine also has beneficial effects on memory and learning processes. Thus, the present review summarizes the potential benefits of nicotine on cognition (Fig. 1).

\section{Benefits of nicotine in Alzheimer's disease (AD)}

$\mathrm{AD}$ is a neurodegenerative disease that primarily affects older adults and causes dementia (27). AD is characterized by the deposition of toxic amyloid- $\beta(\mathrm{A} \beta)$ and tau proteins in the brain $(28,29)$. In particular, the accumulation of $A \beta$ has been demonstrated to inhibit mitochondrial function, leading to increased reactive oxygen species formation and the stimulation of inflammatory processes (30). Indeed, several studies have revealed that $A \beta$ deposition alters the physiological function of the brain and causes neuronal dysfunction $(31,32)$. Unfortunately, there is still no cure for AD, and the disease is currently managed by slowing its progression with the administration of antioxidants and drugs such as cholinesterase inhibitors (33).

According to the cholinergic hypothesis, the cognitive decline in AD arises from deficiencies in central cholinergic neurotransmission due to the loss of acetylcholine (34). Therefore, cholinesterase inhibitors (such as donepezil and galantamine), which block the degradation of acetylcholine, remain the first-line approach to restore central cholinergic function in AD. Moreover, changes in the expression and density of $\alpha_{7} n$ AChRs in the hippocampus have been observed in AD and appear to have the most impact on cognitive function (35). Such $\alpha_{7} \mathrm{nAChRs}$ have also been found to be co-localized with plaques in $\mathrm{AD}$ (36). Therefore, agonists

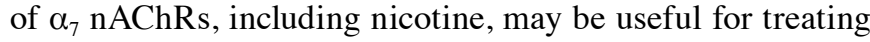
AD.

The stimulation of $\mathrm{nAChRs}$ by nicotine also likely affects downstream signaling molecules, including protein kinases, which are important regulators of synaptic plasticity and memory (37). In particular, protein kinase B (also referred to as $\mathrm{Akt}$ ) is a central molecule of the phosphoinositide 3-kinase (PI3K)/Akt signaling pathway, which plays a vital role in the regulatory functions of neurons in the CNS, including neuronal survival (38-42), and learning and memory encoding $(38,43,44)$. Therefore, it is hypothesized that the stimulation of $\mathrm{nAChRs}$ by nicotine or its analogs activates the PI3K/Akt signaling pathway, which, in turn, regulates learning and memory processes $(42,45)$. Indeed, acute and chronic administration of nicotine was reported to improve cognitive impairment in patients with AD (46-48). Moreover, acute nicotine administration during electroencephalography (EEG) performed in patients with AD who received cholinesterase inhibitors was found to shift the EEG readings towards normal levels (49). Thus, nicotine administration may have a beneficial effect on the cognitive decline observed in AD.

\section{Benefits of nicotine in Parkinson's disease (PD)}

$\mathrm{PD}$ is the second most common neurodegenerative disorder after AD that affects older individuals (50). Although the exact cause of PD is still not fully understood, its pathogenesis involves the loss or degeneration of the dopaminergic neurons (dopamine-producing neurons) in the substantia nigra of the midbrain (51). This loss of dopaminergic neurons causes impairment of motor control, tremors, rigidity and bradykinesia, and cognitive impairment $(52,53)$. Studies in animal models of PD have revealed that nicotine can protect the brain cells from damage $(54,55)$. Smoking cigarettes is also reported to reduce the risk of PD occurrence (53), and nicotine may help improve some symptoms of PD, such as dyskinesia and memory impairments (55). Indeed, the neuroprotective effects of nicotine in PD have been examined in vitro and in vivo, and are hypothesized to be primarily due to its pro-survival effects on dopaminergic neurons (56).

In addition to activating pro-survival signaling pathways in the brain, such as the aforementioned PI3K/Akt pathway, nicotine may also slow the progression of PD by inhibiting Sirtuin 6 (SIRT6), an NAD ${ }^{+}$-dependent class III deacetylase (57). This suppression of SIRT6 was found to reduce apoptosis and increase neuron survival (57). Consistently, several studies reported that the overexpression of SIRT6 impairs contextual fear memory formation $(58,59)$. Despite this, another study found that loss of SIRT6 in the brain also causes memory impairment (60). Therefore, the downstream effects of nicotine on SIRT6 in PD require further investigation.

\section{Benefits of nicotine on memory processes in patients with thyroid disease}

Studies have revealed that thyroid hormones (61), including thyroxine (T4) and triiodothyronine (T3), regulate brain development, neurogenesis, synaptogenesis and myelination $(62,63)$. T3 and T4 are synthesized in the thymus $(64,65)$, released into 
Signaling pathway of nicotine improve memory function

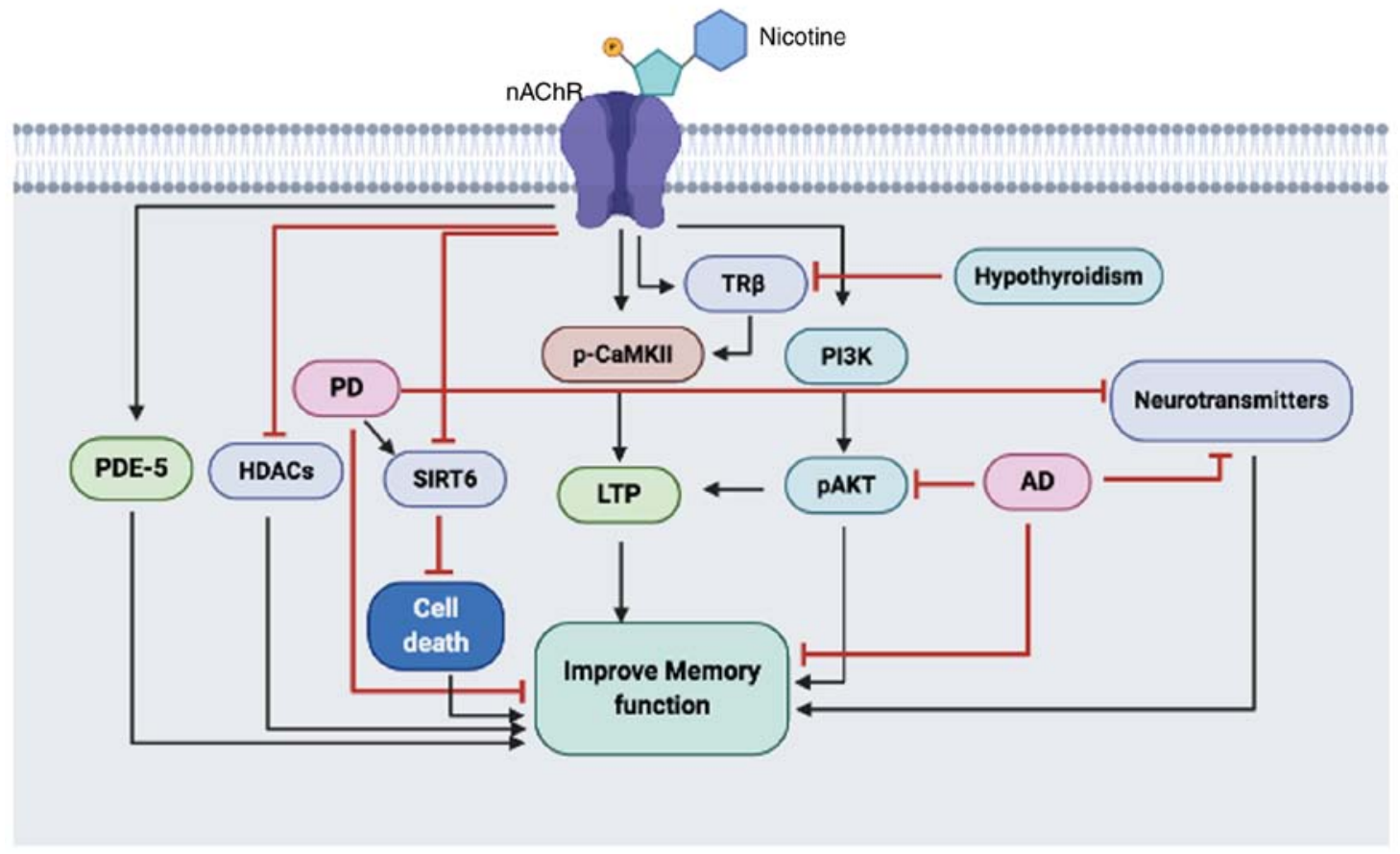

Figure 1. Illustration of the proposed mechanisms of nicotine in improving memory dysfunction. Nicotine activates nAChR, which can activate or inhibit the expression and functions of various proteins. Nicotine can activate PDE-5, TR $\beta$ and CaMKII, and activation of these proteins can lead to increased neuronal communication that ultimately improves memory function. In addition, nicotine activates the pro-survival PI3K/AKT pathway that increases LTP and improves memory dysfunction caused by AD. Also, nicotine can inhibit HDACs and SIRT6, which are increased in PD, thus reducing the activity of these proteins reduces neural apoptosis and improves memory dysfunction. PDE-5, phosphodiesterase-5; HDAC, histone deacetylases; PD, Parkinson's disease; SIRT6, Sirtuin 6; LTP, long-term potentiation; p-, phosphorylated; CAMKII, calmodulin-dependent protein kinase II; TR $\beta$, thyroid receptor subunit $\beta$; PI3K, phosphoinositide 3-kinase; AD, Alzheimer's disease; nAChR, nicotinic cholinergic receptors.

the bloodstream, and eventually exert their effects by binding to a nuclear receptor termed the thyroid hormone receptor (TR), which is present in two different isoforms, $\alpha$ and $\beta$ (66). The expression levels of these isoforms differ among tissues: The $\alpha 1$ receptor is primarily expressed in the heart and the skeletal muscle (67), whereas $\beta 1$ is mainly expressed in the liver, kidney and brain (68).

TRs are also abundantly expressed in the hippocampus, which is the part of the brain that is responsible for memory formation (63). Therefore, in diseases such as hyperthyroidism, hypothyroidism and cretinism, in which abnormal thyroid hormone levels are present $(69,70)$, hippocampal function may be affected, thus resulting in cognitive impairment (71). Indeed, neuroimaging studies have demonstrated that the structure and function of the hippocampus are altered in patients with hypothyroidism (72-74).

Of note, acute nicotine administration has been reported to activate TRs (particularly $\operatorname{TR} \beta$ in the brain) and, thus, may enhance learning and memory processes in certain individuals (66). Furthermore, TR $\beta$ knockout in mice did not affect memory function following nicotine administration, confirming the role of TR $\beta$ in memory processes (75). In addition, memory impairment caused by hypothyroidism was revealed to be improved by nicotine via the modulation of calcineurin, which regulates the function of calmodulin-dependent protein kinase II (CaMKII) to improve synaptic plasticity (76). However, the precise underlying mechanisms of nicotine administration in improving cognitive impairments in patients with thyroid diseases require further investigation.

\section{Effects of nicotine on cognitive function in healthy indi- viduals}

There is mounting evidence that nicotine administration may improve memory in otherwise healthy individuals. For example, research revealed that sleep deprivation causes memory impairment by downregulating the phosphorylation of CaMKII, which is an essential regulator of cell proliferation and synaptic plasticity (77-79). CaMKII was previously found to regulate the expression of glutamate receptor subunit-1 and its trafficking to the synaptic surface, which is necessary for normal brain function and memory formation (80). Consistently, acute nicotine administration was found to improve memory impairments caused by sleep deprivation by enhancing the phosphorylation of CaMKII (81). Therefore, nicotine may improve memory impairments caused by a lack of sleep in otherwise healthy individuals.

\section{Nicotine-induced chromatin modifications may improve memory and learning}

Some studies have indicated that nicotine affects chromatin in the cell nucleus (82-84). Chromatin is composed of four subunits, called histones, which can be modified via acetylation, methylation or phosphorylation (85), thereby regulating gene transcription $(86,87)$. In particular, histone acetyltransferases and histone deacetylases (HDACs) play essential roles in the chromatin modifications involved in various cellular functions, including memory and synaptic 
plasticity $(88,89)$. For example, inhibition of HDACs can increase the expression of key genes involved in memory processes, which are regulated by the cAMP response element-binding protein (CREB)-CREB-binding protein transcriptional complex (89). In particular, HDAC4 has been demonstrated to be crucial for learning and memory processes $(89,90)$. As cigarette smoking has been reported to modulate the regulation of chromatin by altering the functionality of HDACs, such as HDAC6, in the lungs (83), it may also have a similar effect in the CNS. Indeed, it has been revealed that nicotine can inhibit HDACs in the brain, and, thus, improve memory function (84). However, further study is required to investigate the effect of nicotine on cognitive function through chromatin modulation.

\section{Electrophysiological effects of nicotine: Strengthening synapses}

The neurons in the brain interconnect to form networks, which are organized according to function (91). Therefore, understanding these connections allows certain areas to be stimulated and recorded, to monitor neurotransmitter release and receptor response in particular regions of the brain. Long-term potentiation (LTP) is used to measure synaptic plasticity, and can provide a cellular model of learning and memory encoding. For example, an increase in the level of glutamate released from the presynaptic to the postsynaptic neurons was found to enhance excitatory postsynaptic potential in the hippocampus during spatial learning tasks (92). Previously, studies have reported that acute nicotine exposure rescues LTP in individuals with sleep deprivation (81). In addition, chronic administration of nicotine has been revealed to improve LTP in $\mathrm{AD}$, chronic stress models and hypothyroidism models $(74,93,94)$. There is also mounting evidence that the restoration of LTP due to nicotine exposure is related to the normalization of the phosphorylation of essential kinases, such as CREB and CaMKIV $(48,78,95)$. Therefore, nicotine administration may strengthen synapses between two neurons, leading to improved memory in both healthy individuals and those with diseases such as AD or hypothyroidism.

\section{Conclusions}

The findings reported in the studies included in the present review article indicate that nicotine can stimulate memory function. Therefore, although nicotine is similar to other psychoactive substances, in that it can induce dependence or abuse, it also has certain beneficial effects, including enhancing cognitive function in healthy individuals and restoring memory function in patients with diseases, such as $\mathrm{AD}, \mathrm{PD}$ and hypothyroidism.

\section{Acknowledgements}

Not applicable.

\section{Funding}

No funding was received.

\section{Availability of data and materials}

Not applicable.

\section{Author's contributions}

AA designed the review paper, performed the literature search and wrote the manuscript.

\section{Ethics approval and consent to participate}

Not applicable.

\section{Patient consent for publication}

Not applicable.

\section{Competing interests}

The authors declare that they have no competing interests.

\section{References}

1. Benowitz NL, Hukkanen J and Jacob P III: Nicotine chemistry, metabolism, kinetics and biomarkers. Handb Exp Pharmacol 192: 29-60, 2009. doi: 10.1007/978-3-540-69248-5 2.

2. Broide RS, Winzer-Serhan UH, Chen Y and Leslie FM: Distribution of alpha7 nicotinic acetylcholine receptor subunit mRNA in the developing mouse. Front Neuroanat 13: 76, 2019.

3. Mishra A, Chaturvedi P, Datta S, Sinukumar S, Joshi P and Garg A: Harmful effects of nicotine. Indian J Med Paediatr Oncol 36: 24-31, 2015.

4. Bagaitkar J, Demuth DR and Scott DA: Tobacco use increases susceptibility to bacterial infection. Tob Induc Dis 4: 12, 2008.

5. Unwin N: Nicotinic acetylcholine receptor and the structural basis of neuromuscular transmission: Insights from Torpedo postsynaptic membranes. Q Rev Biophys 46: 283-322, 2013.

6. Skok VI: Nicotinic acetylcholine receptors in autonomic ganglia. Auton Neurosci 97: 1-11, 2002.

7. Gotti C, Zoli M and Clementi F: Brain nicotinic acetylcholine receptors: Native subtypes and their relevance. Trends Pharmacol Sci 27: 482-491, 2006.

8. Dani JA: Neuronal nicotinic acetylcholine receptor structure and function and response to nicotine. Int Rev Neurobiol 124: 3-19, 2015.

9. Hone AJ and McIntosh JM: Nicotinic acetylcholine receptors in neuropathic and inflammatory pain. FEBS Lett 592: 1045-1062, 2018.

10. Zaveri N, Jiang F, Olsen C, Polgar W and Toll L: Novel $\alpha 3 \beta 4$ nicotinic acetylcholine receptor-selective ligands. Discovery, structure-activity studies, and pharmacological evaluation. J Med Chem 53: 8187-8191, 2010.

11. Aberger K, Chitravanshi VC and Sapru HN: Cardiovascular responses to microinjections of nicotine into the caudal ventrolateral medulla of the rat. Brain Res 892: 138-146, 2001.

12. Levin ED, Bettegowda C, Blosser J and Gordon J: AR-R17779, and alpha7 nicotinic agonist, improves learning and memory in rats. Behav Pharmacol 10: 675-680, 1999.

13. Hajos M, Hurst RS, Hoffmann WE, Krause M, Wall TM, Higdon NR and Groppi VE: The selective alpha7 nicotinic acetylcholine receptor agonist PNU-282987 [N-[(3R)1-Azabicyclo[2.2.2]oct-3-yl]-4-chlorobenzamide hydrochloride] enhances GABAergic synaptic activity in brain slices and restores auditory gating deficits in anesthetized rats. J Pharmacol Exp Ther 312: 1213-1222, 2005.

14. Benowitz NL: Pharmacology of nicotine: Addiction, smoking-induced disease, and therapeutics. Annu Rev Pharmacol Toxicol 49: 57-71, 2009.

15. D'Souza MS and Markou A: Neuronal mechanisms underlying development of nicotine dependence: Implications for novel smoking-cessation treatments. Addict Sci Clin Pract 6: 4-16, 2011. 
16. Picciotto MR, Addy NA, Mineur YS and Brunzell DH: It is not 'either/or': Activation and desensitization of nicotinic acetylcholine receptors both contribute to behaviors related to nicotine addiction and mood. Prog Neurobiol 84: 329-342, 2008

17. Sun Z, Smyth K, Garcia K, Mattson E, Li L and Xiao Z: Nicotine inhibits memory CTL programming. PLoS One 8 e68183, 2013.

18. Echeverria Moran V: Brain effects of nicotine and derived compounds. Front Pharmacol 4: 60, 2013.

19. Hotston MR, Jeremy JY, Bloor J, Koupparis A, Persad R and Shukla N: Sildenafil inhibits the up-regulation of phosphodiesterase type 5 elicited with nicotine and tumour necrosis factor-alpha in cavernosal vascular smooth muscle cells: Mediation by superoxide. BJU Int 99: 612-618, 2007.

20. Henderson VW: Cognitive changes after menopause: Influence of estrogen. Clin Obstet Gynecol 51: 618-626, 2008

21. Domek-Łopacińska K and Strosznajder JB: Cyclic GMP metabolism and its role in brain physiology. J Physiol Pharmacol 56 (Suppl 2): S15-S34, 2005.

22. Cui Q and So KF: Involvement of cAMP in neuronal survival and axonal regeneration. Anat Sci Int 79: 209-212, 2004.

23. Peixoto CA, Nunes AK and Garcia-Osta A: Phosphodiesterase-5 inhibitors: Action on the signaling pathways of neuroinflammation, neurodegeneration, and cognition. Mediators Inflamm 2015 940207, 2015.

24. Biegon A, Kim SW, Logan J, Hooker JM, Muench L and Fowler JS: Nicotine blocks brain estrogen synthase (aromatase) In vivo positron emission tomography studies in female baboons. Biol Psychiatry 67: 774-777, 2010

25. Bean LA, Ianov L and Foster TC: Estrogen receptors, the hippocampus, and memory. Neuroscientist 20: 534-545, 2014.

26. Luine VN: Estradiol and cognitive function: Past, present and future. Horm Behav 66: 602-618, 2014.

27. Neugroschl J and Wang S: Alzheimer's disease: Diagnosis and treatment across the spectrum of disease severity. Mt Sinai J Med 78: 596-612, 2011.

28. Murphy MP and LeVine H III: Alzheimer's disease and the amyloid-beta peptide. J Alzheimers Dis 19: 311-323, 2010.

29. Deshpande A, Mina E, Glabe C and Busciglio J: Different conformations of amyloid beta induce neurotoxicity by distinct mechanisms in human cortical neurons. J Neurosci 26 : 6011-6018, 2006.

30. Schilling T and Eder C: Amyloid- $\beta$-induced reactive oxygen species production and priming are differentially regulated by ion channels in microglia. J Cell Physiol 226: 3295-3302, 2011

31. Palop JJ and Mucke L: Amyloid-beta-induced neuronal dysfunction in Alzheimer's disease: From synapses toward neural networks. Nat Neurosci 13: 812-818, 2010.

32. Jagust W: Is amyloid- $\beta$ harmful to the brain? Insights from human imaging studies. Brain 139: 23-30, 2016.

33. Mendiola-Precoma J, Berumen LC, Padilla K and Garcia-Alcocer G: Therapies for prevention and treatment of Alzheimer's disease. Biomed Res Int 2016: 2589276, 2016.

34. Grossberg GT: Cholinesterase inhibitors for the treatment of Alzheimer's disease: Getting on and staying on. Curr Ther Res Clin Exp 64: 216-235, 2003.

35. Cheng Q and Yakel JL: The effect of $\alpha 7$ nicotinic receptor activation on glutamatergic transmission in the hippocampus. Biochem Pharmacol 97: 439-444, 2015.

36. Buckingham SD, Jones AK, Brown LA and Sattelle DB: Nicotinic acetylcholine receptor signalling: Roles in Alzheimer's disease and amyloid neuroprotection. Pharmacol Rev 61: 39-61, 2009.

37. Giese KP and Mizuno K: The roles of protein kinases in learning and memory. Learn Mem 20: 540-552, 2013.

38. Diez H, Garrido JJ and Wandosell F: Specific roles of Akt iso forms in apoptosis and axon growth regulation in neurons. PLoS One 7: e32715, 2012.

39. Huang EJ and Reichardt LF: Neurotrophins: Roles in neuronal development and function. Annu Rev Neurosci 24: 677-736, 2001.

40. Del Puerto A, Wandosell F and Garrido JJ: Neuronal and glial purinergic receptors functions in neuron development and brain disease. Front Cell Neurosci 7: 197, 2013.

41. Brunet A, Datta SR and Greenberg ME: Transcription-dependent and -independent control of neuronal survival by the PI3K-Akt signaling pathway. Curr Opin Neurobiol 11: 297-305, 2001.

42. Shu Y, Zhang H, Kang T, Zhang JJ, Yang Y, Liu H and Zhang L: $\mathrm{PI} 3 \mathrm{~K} / \mathrm{Akt}$ signal pathway involved in the cognitive impairment caused by chronic cerebral hypoperfusion in rats. PLoS One 8: e81901, 2013
43. Horwood JM, Dufour F, Laroche S and Davis S: Signalling mechanisms mediated by the phosphoinositide 3-kinase/Akt cascade in synaptic plasticity and memory in the rat. Eur J Neurosci 23: $3375-3384,2006$

44. Chiang HC, Wang L, Xie ZL, Yau A and Zhong Y: PI3 kinase signaling is involved in A beta-induced memory loss in Drosophila. Proc Natl Acad Sci USA 107: 7060-7065, 2010.

45. Yi JH, Baek SJ, Heo S, Park HJ, Kwon H, Lee S, Jung J, Park SJ, Kim BC, Lee YC, et al: Direct pharmacological Akt activation rescues Alzheimer's disease like memory impairments and aberrant synaptic plasticity. Neuropharmacology 128: 282-292, 2018.

46. Newhouse P, Kellar K, Aisen P, White H, Wesnes K, Coderre E, Pfaff A, Wilkins H, Howard D and Levin ED: Nicotine treatment of mild cognitive impairment: A 6-month double-blind pilot clinical trial. Neurology 78: 91-101, 2012.

47. Majdi A, Kamari F, Sadigh-Eteghad S and Gjedde A: Molecular insights into memory-enhancing metabolites of nicotine in brain: A systematic review. Front Neurosci 12: 1002, 2018.

48. Srivareerat M, Tran TT, Salim S, Aleisa AM and Alkadhi KA: Chronic nicotine restores normal $A \beta$ levels and prevents short-term memory and E-LTP impairment in A $\beta$ rat model of Alzheimer's disease. Neurobiol Aging 32: 834-844, 2011.

49. Knott V, Engeland C, Mohr E, Mahoney C and Ilivitsky V: Acute nicotine administration in Alzheimer's disease: An exploratory EEG study. Neuropsychobiology 41: 210-220, 2000.

50. Sherer TB, Chowdhury S, Peabody K and Brooks DW Overcoming obstacles in Parkinson's disease. Mov Disord 27: 1606-1611, 2012

51. Barber M, Stewart D, Grosset D and MacPhee G: Patient and carer perception of the management of Parkinson's disease after surgery. Age Ageing 30: 171-172, 2001.

52. Kinoshita KI, Tada Y, Muroi Y, Unno T and Ishii T: Selective loss of dopaminergic neurons in the substantia nigra pars compacta after systemic administration of MPTP facilitates extinction learning. Life Sci 137: 28-36, 2015.

53. Ma C, Liu Y, Neumann S and Gao X: Nicotine from cigarette smoking and diet and Parkinson disease: A review. Transl Neurodegener 6: 18, 2017.

54. Lu JYD, Su P, Barber JEM, Nash JE, Le AD, Liu F and Wong AHC: The neuroprotective effect of nicotine in Parkinson's disease models is associated with inhibiting PARP-1 and caspase-3 cleavage. PeerJ 5: e3933, 2017.

55. Quik M, O'Leary K and Tanner CM: Nicotine and Parkinson's disease: Implications for therapy. Mov Disord 23: 1641-1652, 2008.

56. Barreto GE, Iarkov A and Moran VE: Beneficial effects of nicotine, cotinine and its metabolites as potential agents for Parkinson's disease. Front Aging Neurosci 6: 340-340, 2015.

57. Nicholatos JW, Francisco AB, Bender CA, Yeh T, Lugay FJ, Salazar JE, Glorioso C and Libert S: Nicotine promotes neuron survival and partially protects from Parkinson's disease by suppressing SIRT6. Acta Neuropathol Commun 6: 120, 2018.

58. Kim H, Kim HS and Kaang BK: Elevated contextual fear memory by SIRT6 depletion in excitatory neurons of mouse forebrain. Mol Brain 11: 49, 2018.

59. Yin X, Gao Y, Shi HS, Song L, Wang JC, Shao J, Geng XH, Xue G, Li JL and Hou YN: Overexpression of SIRT6 in the hippocampal CA1 impairs the formation of long-term contextual fear memory. Sci Rep 6: 18982, 2016.

60. Kaluski S, Portillo M, Besnard A, Stein D, Einav M, Zhong L, Ueberham U, Arendt T, Mostoslavsky R, Sahay A and Toiber D: Neuroprotective functions for the histone deacetylase SIRT6. Cell Rep 18: 3052-3062, 2017.

61. Rousset B, Dupuy C, Miot F and Dumont J: Chapter 2 Thyroid Hormone Synthesis and Secretion. In: Endotext. Feingold KR, Anawalt B, Boyce A, et al. (eds). MDText.com, Inc. South Dartmouth, MA, 2000. https://www.ncbi.nlm.nih.gov/ books/NBK285550/. Accessed September 2, 2015.

62. Diez D, Grijota-Martinez C, Agretti P,De Marco G, Tonacchera M, Pinchera A, de Escobar GM, Bernal J and Morte B: Thyroid hormone action in the adult brain: Gene expression profiling of the effects of single and multiple doses of triiodo-L-thyronine in the rat striatum. Endocrinology 149: 3989-4000, 2008.

63. Desouza LA, Ladiwala U, Daniel SM, Agashe S, Vaidya RA and Vaidya VA: Thyroid hormone regulates hippocampal neurogenesis in the adult rat brain. Mol Cell Neurosci 29: 414-426, 2005.

64. Fekete $\mathrm{C}$ and Lechan RM: Central regulation of hypothalamic-pituitary-thyroid axis under physiological and pathophysiological conditions. Endocr Rev 35: 159-194, 2014. 
65. Mariotti S and Beck-Peccoz P: Physiology of the Hypothalamic-Pituitary Thyroidal System. In: Endotext. De Groot LJ, Beck-Peccoz P, Chrousos G, et al (eds). MDText.com, Inc., South Dartmouth, MA, 2000. https://www.ncbi.nlm.nih. gov/books/NBK278958. Accessed August 14, 2016.

66. Cheng SY: Multiple mechanisms for regulation of the transcriptional activity of thyroid hormone receptors. Rev Endocr Metab Disord 1: 9-18, 2000.

67. Bradley DJ, Towle HC and Young WS III: Spatial and temporal expression of alpha- and beta-thyroid hormone receptor mRNAs, including the beta 2-subtype, in the developing mammalian nervous system. J Neurosci 12: 2288-2302, 1992.

68. Williams GR: Cloning and characterization of two novel thyroid hormone receptor beta isoforms. Mol Cell Biol 20: 8329-8342, 2000.

69. Brent GA: Mechanisms of thyroid hormone action. J Clin Invest 122: 3035-3043, 2012.

70. Yen PM: Physiological and molecular basis of thyroid hormone action. Physiol Rev 81: 1097-1142, 2001.

71. Ge JF, Peng L, Hu CM and Wu TN: Impaired learning and memory performance in a subclinical hypothyroidism rat model induced by hemi-thyroid electrocauterisation. J Neuroendocrinol 24 953-961, 2012

72. Cooke GE, Mullally S, Correia N, O'Mara SM and Gibney J: Hippocampal volume is decreased in adults with hypothyroidism. Thyroid 24: 433-440, 2014.

73. Singh S, Rana P, Kumar P, Shankar LR and Khushu S: Hippocampal neurometabolite changes in hypothyroidism: An in vivo (1) $\mathrm{H}$ magnetic resonance spectroscopy study before and after thyroxine treatment. J Neuroendocrinol: 28, 2016 doi: $10.1111 /$ jne. 12399 .

74. Alzoubi KH, Aleisa AM, Gerges NZ and Alkadhi KA: Nicotine reverses adult-onset hypothyroidism-induced impairment of learning and memory: Behavioral and electrophysiological studies. J Neurosci Res 84: 944-953, 2006.

75. Leach PT, Kenney JW, Connor DA and Gould TJ: Thyroid receptor $\beta$ involvement in the effects of acute nicotine on hippocampus-dependent memory. Neuropharmacology 93: 155-163, 2015.

76. Alzoubi KH, Aleisa AM and Alkadhi KA: Molecular studies on the protective effect of nicotine in adult-onse hypothyroidism-induced impairment of long-term potentiation. Hippocampus 16: 861-874, 2006.

77. Pi HJ, Otmakhov N, El Gaamouch F, Lemelin D, De Koninck P and Lisman J: CaMKII control of spine size and synaptic strength: Role of phosphorylation states and nonenzymatic action. Proc Natl Acad Sci USA 107: 14437-14442, 2010.

78. Aleisa AM, Alzoubi KH, Gerges NZ and Alkadhi KA: Chronic psychosocial stress-induced impairment of hippocampal LTP: Possible role of BDNF. Neurobiol Dis 22: 453-462, 2006.

79. Misrani A, Tabassum S, Wang M, Chen J, Yang L and Long C: Citalopram prevents sleep-deprivation-induced reduction in CaMKII-CREB-BDNF signaling in mouse prefrontal cortex. Brain Res Bull 155: 11-18, 2020.

80. Mao LM, Jin DZ, Xue B, Chu XP and Wang JQ: Phosphorylation and regulation of glutamate receptors by CaMKII. Sheng Li Xue Bao 66: 365-372, 2014.
81. Aleisa AM, Helal G, Alhaider IA, Alzoubi KH, Srivareerat M, Tran TT, Al-Rejaie SS and Alkadhi KA: Acute nicotine treatment prevents REM sleep deprivation-induced learning and memory impairment in rat. Hippocampus 21: 899-909, 2011.

82. Shilatifard A: Chromatin modifications by methylation and ubiquitination: Implications in the regulation of gene expression. Annual Rev Biochem 75: 243-269, 2006.

83. Marwick JA, Kirkham PA, Stevenson CS, Danahay H, Giddings J, Butler K, Donaldson K, Macnee W and Rahman I: Cigarette smoke alters chromatin remodeling and induces proinflammatory genes in rat lungs. Am J Respir Cell Mol Biol 31: 633-642, 2004.

84. Volkow ND: Epigenetics of nicotine: Another nail in the coughing. Sci Transl Med 3: 107ps143, 2011.

85. Kouzarides T: Chromatin modifications and their function. Cell 128: 693-705, 2007.

86. Brehove M, Wang T, North J, Luo Y, Dreher SJ, Shimko JC, Ottesen JJ, Luger K and Poirier MG: Histone core phosphorylation regulates DNA accessibility. J Biol Chem 290: 22612-22621, 2015.

87. Zhang Y, Griffin K, Mondal N and Parvin JD: Phosphorylation of histone $\mathrm{H} 2 \mathrm{~A}$ inhibits transcription on chromatin templates. J Biol Chem 279: 21866-21872, 2004.

88. Legube $\mathrm{G}$ and Trouche D: Regulating histone acetyltransferases and deacetylases. EMBO Rep 4: 944-947, 2003.

89. Vecsey CG, Hawk JD, Lattal KM, Stein JM, Fabian SA, Attner MA, Cabrera SM, McDonough CB, Brindle PK, Abel T and Wood MA: Histone deacetylase inhibitors enhance memory and synaptic plasticity via CREB: CBP-dependent transcriptional activation. J Neurosci 27: 6128-6140, 2007.

90. Kim MS, Akhtar MW, Adachi M, Mahgoub M, Bassel-Duby R, Kavalali ET, Olson EN and Monteggia LM: An essential role for histone deacetylase 4 in synaptic plasticity and memory formation. J Neurosci 32: 10879-10886, 2012.

91. Pulvermuller F, Garagnani $\mathrm{M}$ and Wennekers T: Thinking in circuits: Toward neurobiological explanation in cognitive neuroscience. Biol Cybern 108: 573-593, 2014.

92. Richter-Levin G, Canevari L and Bliss TV: Long-term potentiation and glutamate release in the dentate gyrus: Links to spatial learning. Behav Brain Res 66: 37-40, 1995.

93. Aleisa AM, Alzoubi KH and Alkadhi KA: Nicotine prevents stress-induced enhancement of long-term depression in hippocampal area CA1: Electrophysiological and molecular studies. J Neurosci Res 83: 309-317, 2006.

94. Alkadhi KA: Chronic stress and Alzheimer's disease-like pathogenesis in a rat model: Prevention by nicotine. Curr Neuropharmacol 9: 587-597, 2011.

95. Alzoubi KH and Alkadhi KA: Chronic nicotine treatment reverses hypothyroidism-induced impairment of L-LTP induction phase: Critical role of CREB. Mol Neurobiol 49: 1245-1255, 2014.

This work is licensed under a Creative Commons Attribution-NonCommercial-NoDerivatives 4.0 International (CC BY-NC-ND 4.0) License. 